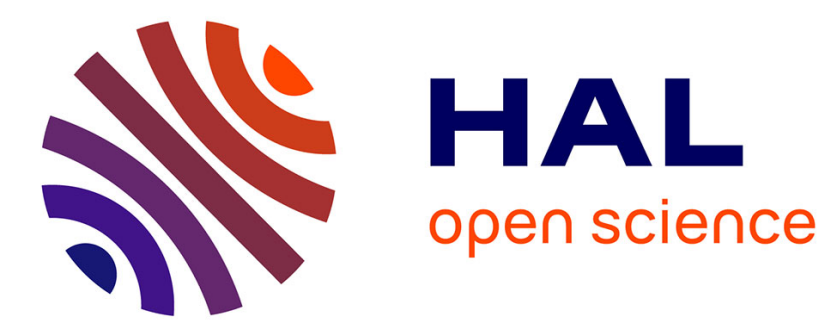

\title{
Millimeter wave carbon nanotube gas sensor
}

M. Dragoman, Katia Grenier, David Dubuc, Laurent Bary, Erwan Fourn, Robert Plana, E. Flahaut

\section{To cite this version:}

M. Dragoman, Katia Grenier, David Dubuc, Laurent Bary, Erwan Fourn, et al.. Millimeter wave carbon nanotube gas sensor. Journal of Applied Physics, 2007, 101 (10), pp.106103. 10.1063/1.2734873 . hal-00392529

\section{HAL Id: hal-00392529 \\ https://hal.science/hal-00392529}

Submitted on 1 Mar 2022

HAL is a multi-disciplinary open access archive for the deposit and dissemination of scientific research documents, whether they are published or not. The documents may come from teaching and research institutions in France or abroad, or from public or private research centers.
L'archive ouverte pluridisciplinaire HAL, est destinée au dépôt et à la diffusion de documents scientifiques de niveau recherche, publiés ou non, émanant des établissements d'enseignement et de recherche français ou étrangers, des laboratoires publics ou privés. 


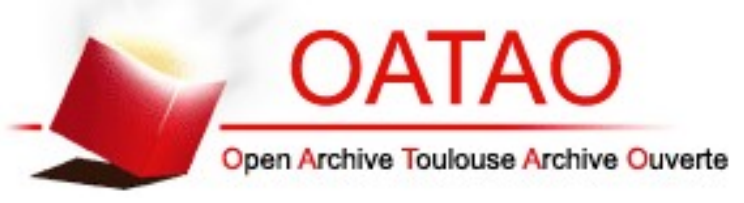

\section{Open Archive Toulouse Archive Ouverte (OATAO)}

OATAO is an open access repository that collects the work of Toulouse researchers and makes it freely available over the web where possible.

This is an author-deposited version published in: http://oatao.univ-toulouse.fr/ Eprints ID : 2471

To link to this article :

URL : http://dx.doi.org/10.1063/1.2734873

To cite this version : Dragoman, M. and Grenier, K. and Dubuc, D. and Bary, L. and Plana, R. and Fourn, E. and Flahaut, Emmanuel ( 2007) Millimeter wave carbon nanotube gas sensor. Journal of Applied Physics, vol. 101 . p. 106103. ISSN 0021-8979

Any correspondence concerning this service should be sent to the repository administrator:staff-oatao@inp-toulouse.fr 


\title{
Millimeter wave carbon nanotube gas sensor
}

\author{
M. Dragoman ${ }^{\text {a) }}$ \\ National Research and Development Institute in Microtechnology, Str. Erou Iancu Nicolae 32 B, \\ 077190 Bucharest, Romania \\ K. Grenier, D. Dubuc, L. Bary, and R. Plana \\ LAAS CNRS, 7 Avenue du Colonel Roche, 31077 Toulouse Cedex 4, France \\ E. Fourn \\ Electronics and Telecommunications Institute of Rennes IETR - UMR CNRS 6164 INSA, \\ 20 avenue des buttes de Coesmes, CS 14315, 35043 RENNES Cedex, France \\ E. Flahaut \\ Centre Interuniversitaire de Recherche et d'Ingénierie des Matériaux, UMR CNRS 5085, \\ Université Paul Sabatier, 31062 Toulouse, France
}

(Received 26 December 2006; accepted 20 March 2007; published online 22 May 2007)

This Letter reports experimental observations regarding the significant changes in the transmission modulus and phase of the propagating microwave signals up to $110 \mathrm{GHz}$ in a micromachined coplanar waveguide supported on a dielectric membrane with a thickness of $1.4 \mu \mathrm{m}$ filled with a mixture of carbon nanotubes when exposed to nitrogen gas. These large shifts of amplitude and phase of microwave signals due to gas absorption represent the experimental basis on which a miniature wireless gas sensor could be implemented. (C) 2007 American Institute of Physics.

[DOI: $10.1063 / 1.2734873$ ]

Carbon nanotubes (CNTs) are considered as the key material for various microwave applications: ${ }^{1}$ passive devices such as filters ${ }^{2}$ or antennas, ${ }^{3}$ active devices such as oscillators, ${ }^{4}$ mixers, ${ }^{5}$ and nanoelectromeachnical systems (NEMS). ${ }^{6}$ New microwave devices are thus designed and implemented using CNTs displaying impressive performances in comparison to similar devices based on present technologies dominated by silicon and AIII-BV semiconductors. These expected performances are based on the amazing physical properties of the carbon nanotubes. For example, CNTs have a huge Young modulus $(\sim 1 \mathrm{TPa})$, the carrier transport is ballistic at room temperature for nanotubes with the mean-free path length around $1 \mu \mathrm{m}$, and for the semiconducting CNTs the carrier mobility could attain even $120000 \mathrm{~cm}^{2} \mathrm{~V}^{-1} \mathrm{~s}^{1}$ at a moderate electric field of $10 \mathrm{kV} / \mathrm{cm}$ (see Ref. 7 for a review of CNT mobility). The band engineering of carbon nanotubes is easily achieved by rolling a graphene sheet at different angles, accompanied by applied transverse electric fields or pressure. ${ }^{8}$

The gas sensors based on the variation of a parameter of CNTs are easily monitored and represent a significant application of CNTs. In this respect, several mechanisms were used to sense various gases. A simple gas sensing mechanism is based on the change of the conductivity of a CNT resistor when the gas is absorbed. ${ }^{9}$ Another gas sensing mechanism originates from the giant thermoelectric effect in CNTs, which was used to implement a nanonose. ${ }^{10}$ In microwave and millimeter wave frequency range, the gas-induced variations of the dielectric permittivity of CNTs mixtures, films, or bundles are used to sense various gases (see Ref. 11 for a

\footnotetext{
${ }^{\text {a) }}$ Corresponding author; electronic mail: mircead@imt.ro;
} mdragoman@yahoo.com recent review). Using this last mechanism, a CNT gas sensor based on a planar circular resonator was implemented by depositing a CNT film on the top of the resonator. The resonant frequency of resonator $f_{0}$ initially at $3.88 \mathrm{GHz}$ is shifted with a frequency shift in the range $0.8-3.91 \mathrm{MHz}$ when the gas is absorbed in CNTs. The value of the frequency shift is directly related to the type of absorbed gas. We have implemented another type of CNT gas sensor based on the gasinduced variations in the dielectric permittivity of carbon nanotubes consisting of a micromachined coplanar waveguide (CPW) supported on a silicon membrane with a thickness of $1.4 \mu \mathrm{m}$ filled with a mixture of double-walled carbon nanotubes (DWCNTs). This planar CNT gas sensor configuration has the important advantage that very large changes in the transmission and phase shifts of microwave signals up to $100 \mathrm{GHz}$ are measured when exposed to nitrogen gas.

The CNT gas sensor configuration is schematically represented in Fig. 1. The DWNTs are fabricated by the catalytic decomposition of methane over a CoMo-MgO catalyst. The DWCTs are very pure and have known and verifiable electrical, magnetic, and optical properties and are produced

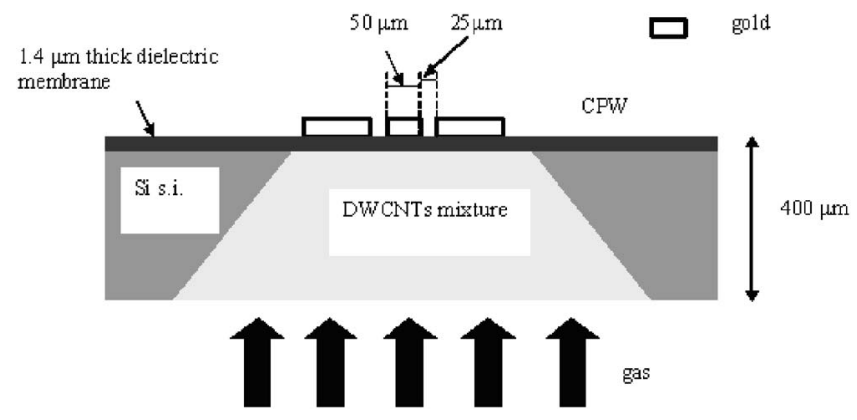

FIG. 1. Millimeterwave gas sensor based on carbon nanotubes. 


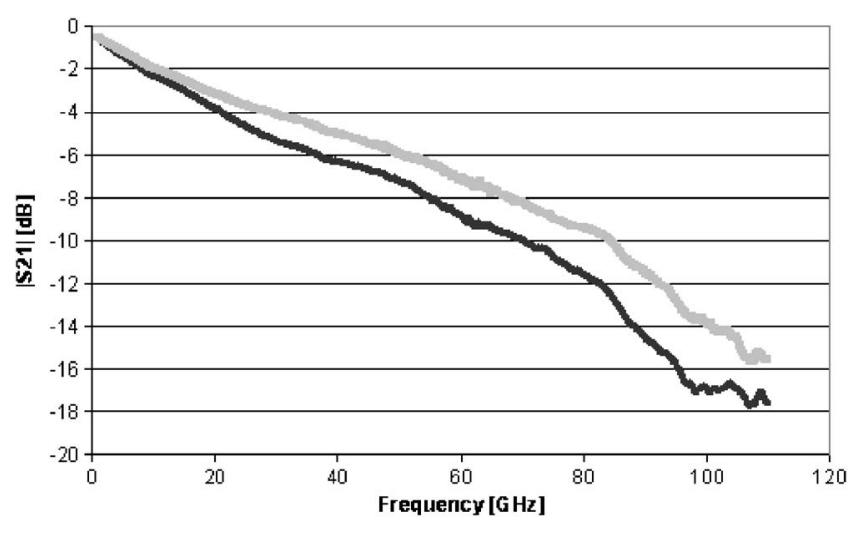

FIG. 2. Modulus of $S_{21}$ before (black solid line) and after (gray solid line) gas absorption.

in house by Flahaut. In Ref. 12 one can find a detailed list of references about the DWCNT production and characterization, and two scanning electron microscope (SEM) photos of this mixture. The DWCNTs have an average diameter of 2 $\mathrm{nm}$ and an average length of $10 \mu \mathrm{m}$. We have introduced this mixture in a CPW supported on a thin dielectric membrane (see Fig. 1) which, in the absence of the CNT material, displays an almost dielectric constant near 1 and thus has very low losses in a very wide band of frequencies 1-110 GHz. This microwave CPW supported on a dielectric membrane has a length of $2 \mathrm{~mm}$ terminated on both sides by standard $50 \Omega$ lines and was fabricated ${ }^{12}$ by micromaching of a semiinsulator (s.i.) Si substrate having a $400 \mu \mathrm{m}$ thickness. Although the dielectric membrane is only $1.4 \mu \mathrm{m}$ thick, it is very reliable because no failure was observed during numerous manipulations and experiments. The mixture of the carbon nanotubes was manually introduced into the cavity of the micromachined $\mathrm{CPW}$ with the help of a tweezers, trying for uniform deposition with a high filling factor exceeding $90 \%$. The filling factor was estimated in Ref. 12 using a SEM inspection of a CNT mixture sample and later confirmed by the measurement of the permittivity and computing of field penetration in the CNT mixture.

The transmission parameter of the CPW filled with CNTs, denoted $S_{21}$, was measured in the range $1-110 \mathrm{GHz}$ using calibrated measurements with the help of a vector network analyzer. The modulus and phase of $S_{21}$ were measured in two situations, i.e., CPW filled with CNT, and CPW filled with CNT after $15 \mathrm{~h}$ of exposure to nitrogen gas having a low pressure of 5 bar. These measurements are displayed in Figs. 2 and 3. From Figs. 2 and 3 we can observe large differences in the modulus and phase before and after gas absorption. For example, at $60 \mathrm{GHz}$ there is a $2 \mathrm{~dB}$ difference in transmission modulus and $25 \mathrm{deg}$ of phase shift. The recovery time was several hours at room temperature. The recovery time is long for all CNT gas sensors and varies from tens of minutes up to few hours depending upon the sensing mechanism. However, in Ref. 9 it was demonstrated that this long recovery time can be reduced to a few minutes

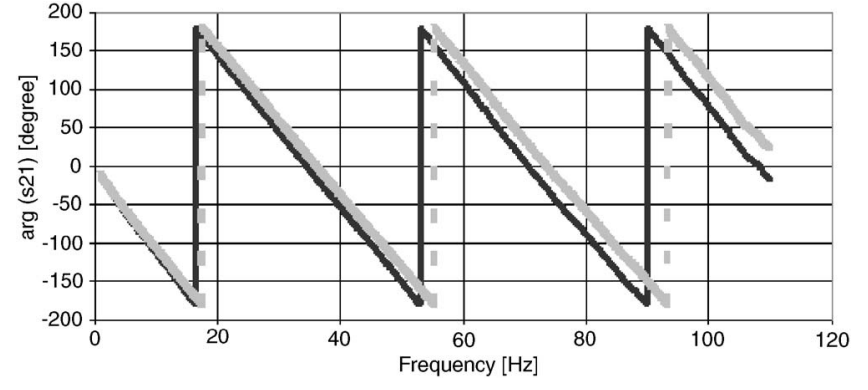

FIG. 3. Phase of $S_{21}$ before (black solid line) and after (gray solid line) gas absorption.

if the CNT mixture is periodically heated with the help of a thin metal film heater located beneath the CNT mixture. The cycling heating from room temperature up to $120^{\circ} \mathrm{C}$ with the help of a miniaturized heater is used to change the desorption rate of the gases. The above results displayed in Figs. 2 and 3 demonstrate that a very sensitive gas sensor having a moderate recovery time can be built at millimeter-wave frequencies. Choosing $60 \mathrm{GHz}$ or even $100 \mathrm{GHz}$ as the working frequency, one could remotely transmit the sensor data via a simple communication system. This is important in all applications where we do not have a direct access to measure gas leakages and their influence to the environment, or in applications where an array of gas sensors must be remotely monitored. This Letter thus illustrates that nanotechnologies are capable of enhancing the wireless sensor capabilities combing new materials like CNTs with advanced microwave devices (see Ref. 13 for a recent review regarding nanotechnology-enabled wireless sensors).

The authors acknowledge support through the EU Network of Excellence AMICOM.

${ }^{1}$ M. Dragoman, H. Hartangel, J. Tuovinen, and R. Plana, Frequenz 59, 251 (2005).

${ }^{2}$ J. F. Davies, M. Bronikowski, D. Choi, L. Epp, M. Hoen, D. Hoppe, B. Kowalczyk, F. Noca, E. Wong, B. Hunt, B. Chang, M. Jouzi, M. Tzalov, A. Yin, J. Xu, D. Adam, R. Yang, J. Adams, and B. Rogers, in Third IEEE Conference on Nanotechnology IEEE-NANO, August 2003, San Francisco, Vol. 2, pp. 635-638.

${ }^{3}$ G. W. Hanson, IEEE Trans. Antennas Propag. 53, 3426 (2005).

${ }^{4}$ D. Dragoman and M. Dragoman, Phys. Rev. B 73, 125417 (2006).

${ }^{5}$ R. Rosenblatt, H. Lin, V. Sazonova, S. Tiwari, and P. L. McEuen, Appl. Phys. Lett. 87, 153111 (2005).

${ }^{6}$ H. B. Peng, C. W. Chang, S. Aloni, T. D. Yuzvinsky, and A. Zettl, Phys. Rev. Lett. 97, 087203 (2006).

${ }^{7}$ T. Dürkop, B. M. Kim, and M. S. Fuhrer, J. Phys. Condens. Matter 16, R553 (2004).

${ }^{8}$ M. Dragoman and D. Dragoman, Nanoelectronics. Principles and Devices (Artech House, Norwood, MA, 2006).

${ }^{9}$ W.-S. Cho, S.-I. Moon, Y.-D. Lee, Y.-H. Lee, J.-H. Park., and B. K. Ju, IEEE Electron Device Lett. 26, 498 (2005).

${ }^{10}$ C. K. W. Adu, G. U. Sumanasekera, B. K. Pradhan, H. E. Romero, and P. C. Eklund, Chem. Phys. Lett. 337, 31 (2001).

${ }^{11}$ F. Picaud, R. Langel, M. Arbam, M. Devel, C. Giradet, S. Natarajan, S. Chopra, and A. M. Rao, J. Appl. Phys. 97, 114316 (2005).

${ }^{12}$ M. Dragoman, K. Grenier, D. Dubuc, L. Bary, E. Fourn, R. Plana, and E. Flahaut, Appl. Phys. Lett. 88, 153108 (2006).

${ }^{13}$ J. P. M. She and J. T. W. Yeow, IEEE Sens. J. 6, 1331 (2006). 